\title{
Prevalence of haemoparasites in pet, working and stray dogs of Assam and North-East India: A hospital based study
}

\author{
K. Bhattacharjee and P. C. Sarmah \\ Department of Parasitology, College of Veterinary Science, \\ Assam Agricultural University, Khanapara, Guwahati-781022, Assam, India \\ Corresponding author: K. Bhattacharjee, email: kantabhatta@gmail.com \\ Received: 03-07-2013, Revised: 01-09-2013, Accepted: 03-09-2013, Published online: 08-10-2013
}

doi: 10.14202/vetworld.2013.874-878

How to cite this article: Bhattacharjee K and Sarmah PC (2013) Prevalence of haemoparasites in pet, working and stray dogs of Assam and North-East India: A hospital based study, Veterinary World 6(11): 874-878.

\begin{abstract}
Aim: This research work is aimed to find out the prevalence of haemoparasitic infections in different categories of dogs.

Materials and Methods: Out of 2104 dogs registered in the Teaching Veterinary Clinical Complex of the College of Veterinary Science, Khanapara, Guwahati during January 2009 to December 2010, blood of 424 cases suspected for haemoparasites on the basis of clinical history were microscopically examined in wet blood film and giemsa stained blood smears.

Results: The prevalence was $57.31 \%$ in the hospital population comprising pet $(58.03 \%)$ and working $(54.54 \%)$ dogs and $63.64 \%$ in stray dog population. A total of 7 species viz. Babesia gibsoni (47.16\%), Ehrlichia (Anaplasma) platys (8.49\%), Dirofilaria immitis (2.83\%), Ehrlichia canis $(2.12 \%)$, Babesia canis $(1.41 \%)$, Hepatozoon canis $(1.41 \%)$ and Ehrlichia ewingii $(0.47 \%)$ in single or mixed infections were recorded. B. gibsoni was found to be most predominant haemoprotozoan species. However, B. canis, the large form of Babesia was detected in very few dogs. Similarly, inclusion of E. platys inside blood platelets, although rare in occurrence, was more easily detectable than that of $E$. canis inside the monocytes and lymphocytes. Infection with $D$. immitis in pet $\operatorname{dogs}(2.38 \%)$ was comparatively lower than in working $\operatorname{dogs}(4.54 \%)$ and found in single and mixed infections with B. gibsoni, B. canis and E. platys. Hepatozoon canis was recorded in 6 hospital dogs either in single or mixed infection with $B$. gibsoni and $E$. platys. Six species of haemoparasites namely B. gibsoni (47.72\%), D. immitis (27.27\%), E. platys (4.54\%), E. canis (2.27\%), E. ewingii (2.27\%) and H. canis (2.27\%) were detected in blood of stray dogs. Trypanosoma evansi as recorded in dogs from other parts of the country was not detected in this study.
\end{abstract}

Conclusion: Present findings led to a significant conclusion that Assam and adjoining states of North East region of India are highly enzootic for the vector borne haemoparasites of dog.

Keywords: Babesia, Dirofilaria, dog, Ehrlichia, haemoparasite, Hepatozoon

\section{Introduction}

Dogs are known to be infected by different haemoparasites viz. Babesia spp, Trypanosoma spp, Leishmania spp, Hepatozoon spp, Ehrlichia spp, Anaplasma spp, Mycoplasma spp (Haemobartonella) and Dirofilaria $s p$ which are transmitted through different arthropod vectors like ticks, lice, triatomines, mosquitoes, tabanids and phlebotomine sand flies and produce illness collectively termed as canine vector borne diseases (CVBD) in tropical and subtropical countries including India. Some of them are often known to have zoonotic importance [1]. Available reports from India [2,3] revealed canine babesiosis and ehrlichiosis to have gained increased significance in the recent years. Ministry of Environment and Forest, Govt. of India also emphasized that the North-eastern states and other three regions namely Himalayan, Coastal and Western Ghats of the country are vulnerable to climate change characterized by increased rainfall and environmental temperature

Copyright: The authors. This article is an open access article licensed under the terms of the Creative Commons Attribution License (http://creativecommons.org/licenses/by/2.0) which permits unrestricted use, distribution and reproduction in any medium, provided the work is properly cited. resulting likelihood of increased vector borne diseases including human malaria. Information pertaining to the status of haemoparasite infections in dogs of North east region of India is very scanty.

The present paper communicates the results of a systematic study on the prevalence of haemoparasitic infections in dogs of Assam and adjoining states of North East India.

\section{Materials and Methods}

Ethical approval: The experiments comply with the guidelines laid down by the Institutional Ethical Committee and in accordance with the country law.

Study period: The study was conducted for a period of 2 years from January 2009 to December 2010.

Study area: The study was carried out in two dog populations, namely stray dog population and hospital population comprising pet dogs owned by private owners in different parts of Assam and working dogs under Central Paramilitary Forces (CRPF, SSB, BSF, NDRF, ITBP, CISF) posted in different parts of Assam, Meghalaya, Manipur, Tripura, Arunachal Pradesh, and the State Police department (Assam Police). 
Table-1. Prevalence of haemoparasites in hospital and stray dog population

\begin{tabular}{llcccc}
\hline Source & Group & No. registered & No. examined & No. infected & \% Positive \\
\hline Hospital population & Pet & 2016 & 336 & 195 & 58.03 \\
& Working & 88 & 88 & 48 & 54.54 \\
Sub Total & & 2104 & 424 & 243 & 57.31 \\
Stray dog population & Stray & - & 44 & 28 & 63.64 \\
Total & & 2104 & 468 & 271 & 57.90 \\
\hline
\end{tabular}

Table-2. Species-wise prevalence of haemoparasite infection in hospital and stray dog populations

\begin{tabular}{llccccc}
\hline Parasite species & \multicolumn{3}{c}{ Hospital population (n=424) } & \multicolumn{2}{c}{ Stray dog population (n=44) } \\
\cline { 2 - 7 } & $\begin{array}{l}\text { \% as Single } \\
\text { infection (No.) }\end{array}$ & $\begin{array}{c}\text { \% as Mixed } \\
\text { infection (No.) }\end{array}$ & \% Total (No.) & $\begin{array}{c}\text { \% as Single } \\
\text { infection (No.) }\end{array}$ & $\begin{array}{l}\text { \% as Mixed } \\
\text { infection (No.) }\end{array}$ & \% Total (No.) \\
\hline Babesia gibsoni & $42.68(181)$ & $4.48(19)$ & $47.16(200)$ & $29.54(13)$ & $18.18(8)$ & $47.72(21)$ \\
Babesia canis & $1.18(5)$ & $0.23(1)$ & $1.41(6)$ & - & - & - \\
Ehrlichia canis & $1.41(6)$ & $0.70(3)$ & $2.12(9)$ & - & $2.27(1)$ & $2.27(1)$ \\
Ehrlichia ewingii & $0.23(1)$ & $0.23(1)$ & $0.47(2)$ & - & $2.27(1)$ & $2.27(1)$ \\
Ehrlichia platys & $3.53(15)$ & $4.95(21)$ & $8.49(36)$ & - & $4.54(2)$ & $4.54(2)$ \\
Dirofilaria immitis & $1.41(6)$ & $1.41(6)$ & $2.83(12)$ & $13.64(6)$ & $13.64(6)$ & $27.27(12)$ \\
Hepatozoon canis & $0.94(4)$ & $0.47(2)$ & $1.41(6)$ & - & $2.27(1)$ & $2.27(1)$ \\
Trypanosoma evansi & 0.0 & 0.0 & 0.0 & 0.0 & 0.0 & 0.0 \\
\hline
\end{tabular}

Population size: During the study period, a total of 2104 hospital dogs were brought to the Teaching Veterinary Clinical Complex of the College of Veterinary Science, Assam Agricultural University, Khanapara, Guwahati, Assam for treatment of various ailments, routine health check-up and vaccination. Of these, 424 dogs considered suspicious for having haemoparasitic infection on the basis of case history (depression, inappetance, lethargy, fever, abnormal coloration of stool and urine and history of tick attachment) were examined in the present study. The stray dog population consisted of 44 local non-descript adult street dogs of either sex captured from different places of Guwahati city. These animals were captured by a non-government organization "JBF" (Just Be Friendly) for sterilization under a project sponsored by the Animal Welfare Board of India, New Delhi.

Sample collection: Blood samples were collected in vials containing EDTA anticoagulant from the hospital dogs at their first clinical presentation and from stray dogs at the time of sterilization operation.

Blood examination: Parasitological examination by microscopy was performed in wet blood film preparation for detection of microfilaria and in giemsa stained thin blood smear for all haemoparasites. Buffy coat examination was done selectively to detect Ehrlichia infection in similar giemsa stained white blood cells. The parasites were identified on the basis of characteristic morphology. Parasitaemia in positive cases was estimated by counting at least 10 randomly chosen oil immersion fields containing a single layer of non-overlapping cells in the stained smear. In the cases where quantitative estimation was not possible, parasitaemia was graded as rare, occasional and frequent $(<1 \%)$. Failure to detect parasite in the smear after evaluating at least 500 oil immersion fields in 2030 minutes time was declared as microscopically negative blood sample.

Statistical analysis: Data on prevalence were analyzed using Statistical Package for Social Science (SPSS) version 17.0 (SPSS Inc. Chicago, IL, USA) and subjected to statistical analysis. Chi-square test of association was used to establish the association.

\section{Results}

Examination of blood performed in hospital dogs on the basis of clinical symptoms revealed $57.31 \%$ (243/424) cases haemoparasite positive. Of which, $58.03 \%$ and $54.54 \%$ infections were recorded in pet and working dogs respectively (Table-1). Microscopic examination of blood from stray dogs revealed $63.64 \%$ haemoparasite infection. There was no significant difference in the prevalence rate of haemoparasites among pet, working and stray dogs $(\mathrm{P}<0.05)$. Prevalence data when plotted in the geographical map of the North East region of India revealed 14 out of 27 districts of Assam to be affected with haemoparasites.

In hospital population (pet and working dogs), 7 species of haemoparasites viz. Babesia gibsoni (47.16\%), Ehrlichia (Anaplasma) platys (8.49\%), Dirofilaria immitis $(2.83 \%)$, Ehrlichia canis $(2.12 \%)$, B. canis (1.41\%), Hepatozoon canis $(1.41 \%)$ and Ehrlichia ewingii $(0.47 \%)$ in single or mixed infection was recorded (Table-2) with $B$. gibsoni found to be the most frequent. In the case of stray dogs, blood examination revealed 6 species viz. B. gibsoni (47.72\%), D. immitis (27.27\%), E. platys (4.54\%), E. canis $(2.27 \%)$, E. ewingii $(2.27 \%)$ and $H$. canis (2.27\%). T. evansi was not detected in blood of either stray or hospital dogs during the study period. Babesia gibsoni was observed in the red blood cells (Figure-1) of hospital dogs with parasitaemia varying from rare to as high as $30 \%$. B. canis, the large form of Babesia (Figure-2) was detected having rare to occasional parasitaemia.

Among the Ehrlichia sps, Ehrlichia (Anaplasma) platys (Figure-3) was most frequently detected as mono infection (3.53\%) and co-infection (4.95\%) with Babesia, E. canis, H. canis and D. immitis in the hospital dogs followed by Ehrlichia canis (Figure-4). Microfilariae of D. immitis (Figure-5) was 


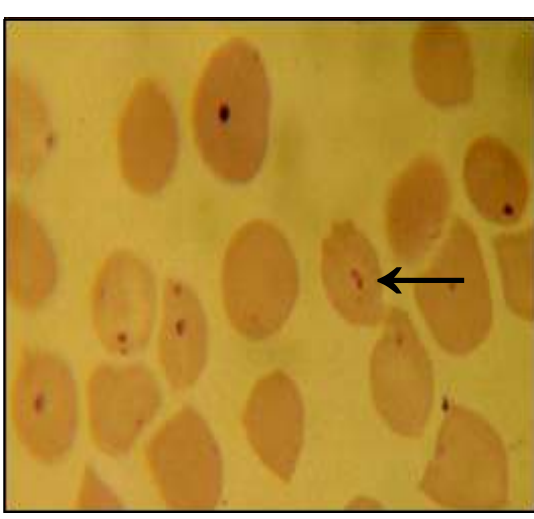

Figure-1. Babesia gibsoni dot with vacuole and band form

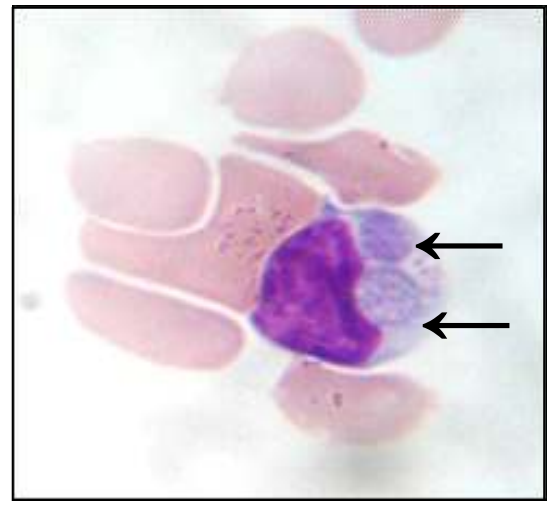

Figure-4. E. canis morulae in a monocyte

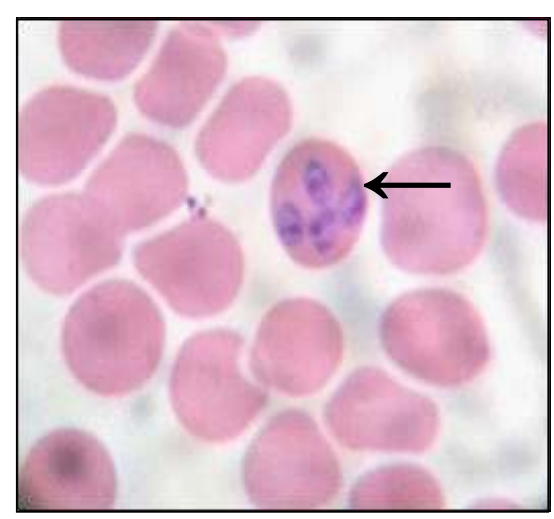

Figure-2. Babesia canis pear shaped merozoites in pairs

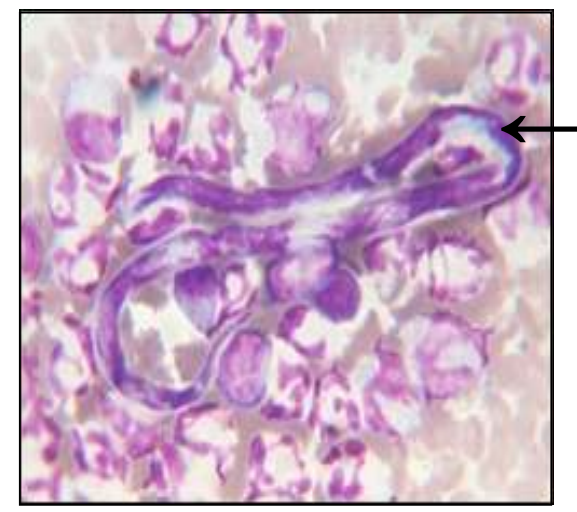

Figure-5. Dirofilaria immitis microfilaria in blood smear

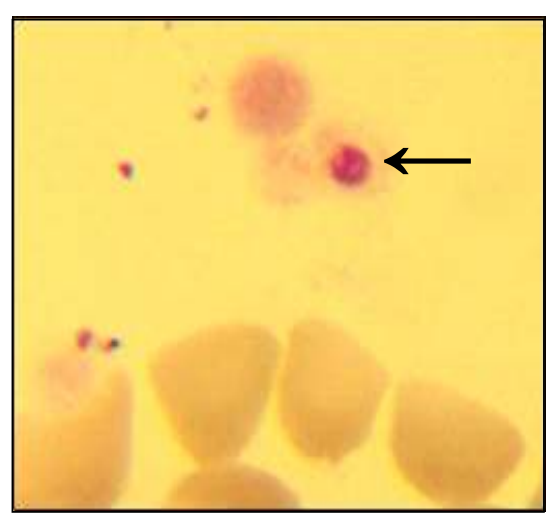

Figure-3. Ehrlichia (Anaplasma) platys inclusion in one out of three platelets

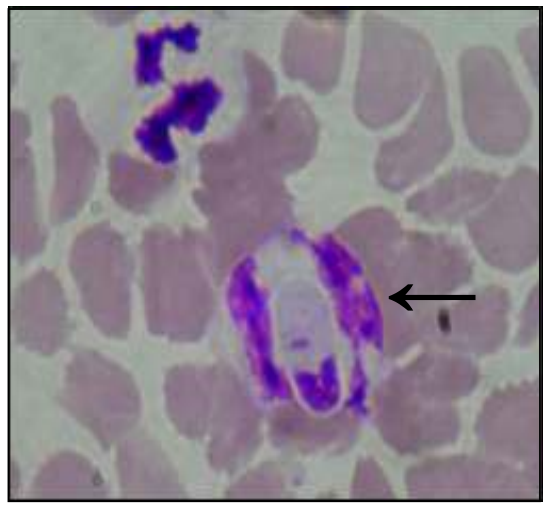

Figure-6. Hepatozoon canis gamete inside neutrophil detected in $4.54 \%$ working dogs and $2.38 \%$ pet dogs with an overall $2.83 \%$ detection in hospital dogs in single and mixed infection with $B$. gibsoni, B. canis and $E$. platys. In the case of stray dogs microfilaria was detected in $27.27 \%$ cases. However, wet blood film examination could detect higher number of $D$. immitis positive cases which were $4.76 \%, 7.95 \%$ and $29.54 \%$ in pet, working and stray dogs respectively.

In respect of Hepatozoon canis, a total of $7 \mathrm{dogs}, 6$ from the hospital population and one stray dog of the present study were found positive either in single or mixed infection with $B$. gibsoni and E. platys. Gelatin capsule shaped gametes of $H$. canis were found in the cytoplasm of neutrophils (Figure-6).

\section{Discussion}

Higher prevalence of blood parasites in stray dogs than in the pets was also reported by Gadahi et al [4]. Considering all the 2104 ailing dogs attending the hospital and the stray dogs examined, prevalence of haemoparasites could be estimated at $12.61 \%$. Information on the prevalence of haemoparasites in dog of this region is too scanty to compare with the present findings. Prevalence of 11.6-16.39\% in dogs were reported by Senthil Kumar et al. from Chennai (Tamil Nadu) [3], Eljadar Mohamed et al. from Jaipur (Rajasthan) [5] and Godara et al from Ludhiana (Punjab) [6]. Highest infection rate with $B$. gibsoni (84.9\%) followed by E. canis, H. canis and B. canis was similarly reported by Senthil Kumar et. al. [3].
Results pertaining to Ehrlichia are also in agreement with Varshney [2] who has mentioned E. platys and granulocytic Ehrlichia as co-infection with E. canis and/or concurrent infection with Babesia, Dirofilaria, Hepatozoon and also Trypanosoma. Occasional appearance of $B$. canis in the peripheral blood of dogs was also mentioned by Irwin [7]. Referring to one clinical case, microscopic examination of 2 blood smears from the moderately anaemic dog revealed presence of $B$. canis in only one red blood cell of a thin smear. The parasite could not be detected in subsequent examination of blood of this animal 6 months later when presented with severe anaemia for antibabesial treatment. This observation agreed with Schalm et al [8] who reported demonstration of the parasite was a fortunate occurrence in 1 out of 5 blood examinations done in a Babesia canis positive dog during a month followed by subsequent failure when the dog was kept under close observation for another 10 months. Due to technical constraints, B. canis could not be detected on microscopic examination, which requires better detection methods [9]. Difficulty in detection of $B$. canis was also mentioned by Soulsby [10] and treatment of which in endemic areas required to be mostly based on exhibited clinical symptoms. Lower incidence of B. canis than B. gibsoni observed in the present study was also recorded by Senthil Kumar et al. [3].

Although serological test was not performed to confirm inclusions of E. platys in the platelets, 
oxytetracycline and/or doxycycline therapy in positive cases resulted in disappearance of clinical signs and improvement of general health condition of the treated dogs [9]. Frequent detection of E. platys (14.81\%) in haemoparasite positive cases of the present study was also in agreement with Ferreira et al [11] who recorded $14.85 \%$ E. platys by microscopy against $15.84 \%$ positivity in PCR thus claiming blood smear analysis as a good and trustable alternative to PCR analysis. Experience gathered in the present study revealed that microscopic detection of $E$. platys was easier than that of $E$. canis. This conformed to the reports of Greene, et al [12] and Mylonakis et al [13] who opined that blood and buffy coat examination for detection of $E$. canis was unrewarding due to transient appearance of $E$. canis in the monocyte or lymphocytes of peripheral blood in only $4 \%$ of the positive dogs with acute phase of infection.

With regard to D. immitis, Borthakur et al [14] recorded $33.75 \%$ of slaughtered stray dogs having adult heartworms in Mizoram, India. Of which, $21.66 \%$ were microfilaraemic and remaining $12.08 \%$ with occult infection. D. immitis was recorded earlier by Borthakur, et al from Mizoram [14], Kumar et al from Uttar Pradesh [15] and Laha et al from West Bengal [16]. Present finding of D. immitis in Assam also conformed to the report of Megat Abd Rani et al [17] who opined that D. immitis was restricted to India's north east and extending northward to Delhi. Prevalence of $H$. canis in pet and stray dogs from different parts of India was earlier recorded by Eljadar Mohamed et al [5].

Prevalence of haemoparasites- highest in stray dogs followed by pet and working dogs as observed in the present study led to a significant conclusion that Assam and adjoining North Eastern states of India were highly enzootic for the vector borne haemoparasites in dog. Favorable climate with moderate temperature and high humidity, unabated movement of dogs within the country and even international transportation might have influenced their prevalence. Moreover Rhipicephalus sanguineus, the proven vector of babesiosis, ehrlichiosis and hepatozoonosis [18] has been reported to be the common tick of dog in Assam [19]. Despite of tremendous development in detection of these parasitic infections by the modern serological and molecular methods, access to these techniques for routine clinical diagnosis is still restricted to a few laboratories worldwide [7]. In the absence of a cost effective and easily available rapid diagnostic kit, microscopy, "the gold standard" [20] still remains to be the choice of veterinarians engaged in the field of diagnosis and treatment.

\section{Conclusion}

Present findings led to a significant conclusion that Assam and adjoining states of North East region of India are highly enzootic for the vector borne haemoparasites of dog.

\section{Authors' contributions}

KB: Collection of blood samples and photography; KB and PCS: Detailed microscopic examination of blood, conception, preparation and revision of the article. Both authors read and approved the final manuscript.

\section{Acknowledgements}

The authors are thankful to the Dean, Faculty of Veterinary Science and Director Post Graduate Studies, AAU, Khanapara for providing financial assistance. Help and facilities provided by Dr. Sashanka Dutta, Trustee, J.B.F Guwahati, Dr. Bitupona Deuri and Dr. Lalit Deori to carry out the research are also duly acknowledged.

\section{Competing interests}

The authors declare that they have no competing interests.

\section{References}

1. Saritas K, Ifikar., Kadir, Z., Akin, F., Pahal, M. and Cal, N. (2005) Open Heart Surgery Applications in Dogs suffering from natural infection of Dirofilaria immitis. Turk. J. Vet. Anim. Sci. 29: 713-721.

2. Varshney, J.P. (2005) Canine ehrlichiosis: an emerging problem in India. Proc. Nat. Acad. Sci. India. 75: 95-108.

3. Senthil Kumar, K., Vairamuthu, S. and Kathiresan, D. (2009) Prevalence of haemoprotozoans in Canines in Chennai city. TamilNadu J. Vet. Anim. Sci. 5: 104-108.

4. Gadahi, J.A., Arijo, A.G., Abubakar, M., Javaid, S. B. and Arshad, M.J. (2008) Prevalence of blood parasites in stray and pet dogs in Hyderabad area: Comparative sensitivity of different diagnostic techniques for the detection of microfilaria. Vet. World. 1:229-232.

5. Eljadar Mohamed, S.M., Singla, L.D., Uppal, S.K., Bal, M.S. and Juyal, P.D. (2010) Studies on morphometric variations of haematozoa in dogs. (Abstr). XX National Congress of Veterinary Parasitology. Hisar, Haryana.

6. Godara, R., Sharma, R.L., Sharma, C.S. and Sharma, D.K. (2010) Parasitic infections in dogs in semi-arid Jaipur (Rajasthan). J. Vet. Parasitol. 24: 83-86.

7. Irwin, P.J. (2009) Canine babesiosis: from molecular taxonomy to control. Parasites \& Vectors. 2: S4.

8. Schalm, O.W., Jain, N.C., Carrol, E.J. (1975) Veterinary Haematology. $3^{\text {rd }}$ Edition, Lea and Febiger, Philadelphia, U.S.A.Pp.807.

9. Bhattacharjee, K. (2011) Studies on haemoparasitic infections of dog with special reference to Dirofilaria immitis. PhD Thesis submitted to Assam Agricultural University, Khanapara, Guwahati, India.

10. Soulsby, E.J.L. (1982) Helminths, Arthropods and Protozoa of domesticated animals. $7^{\text {th }}$ Edn. ELBS Bailliere and Tindall, London. Pp.809.

11. Ferreira, R.F., Cerqueira, A.D.F., Pereira, A.M., Guimarães, C.M., Garcia de Sá, A., da Silva Abreu, F., Massard, C.L., Almosny, N.R.P. (2007) Anaplasma platys Diagnosis in Dogs: Comparison Between Morphological and Molecular Tests. Intern. J. Appl. Res. Vet. Med. 5:113-119.

12. Greene, C.E. and Harvey, J.W. (1984) Canine Ehrlichiosis. In: Clinical Microbiology and Infectious Disease of the Dog and Cat. Philadelphia, W.B. Saunders Co. pp 545-561.

13. Mylonakis, M.E., Koutinas,' A.F., Billinis, C., Leontides, L.S., Kontos, V., Papadopoulos, O., Rallis, T. and Fytianou, A. (2003) Evaluation of cytology in the diagnosis of acute canine monocytic ehrlichiosis (Ehrlichia canis): a comparison between five methods. Vet. Microbiol. 91:197-204.

14. Borthakur, S.K., Sarmah, K., Rajkhowa, T.K., Das, M.R. and Rahman, S. (2006) Dirofilaria immitis infection in dog. J. Vet. Parasitol. 20: 167-169. 
15. Kumar, A. and Varshney, J.P. (2007) Clinico-haematological and biochemical investigations in dogs concurrently infected with Anaplasma platys and other blood parasites. J. Vet. Parasitol. 21: 43-45.

16. Laha, R., Bhattacharya, D., Ramakrishna, C., Das, S.C., Roy, R.N., Bandyopadhyay, U.K., De, D.K., Chakraborty, C.K. and Sikdar, A. (2002) Detection of microfilaria of Dirofilaria immitis in canine and its treatment: A case report. J. Vet. Parasitol. 16: 183-184.

17. Megat Abd Rani, P.A., Irwin, P.J., Gatne, M., Coleman, G.T., McInnes, L.M., Traub, R.J. (2010) A survey of canine filarial diseases of Veterinary and Public health significance in
India. Parasites \& Vectors. 3: 30-53.

18. Ayoob, A.L., Hackner, S.G. and Prattle, J. (2010) Clinical management of canine babesiosis. J. Vet. Emerg. Crit. Care. 20: 77-89.

19. Lahkar, B.C. (1991) Studies on Ixodid ticks with special reference to Boophilus microplus (Canestrini, 1887). $\mathrm{PhD}$ Thesis submitted to Assam Agricultural University, Khanapara, Guwahati, India.

20. Ravindran, R., Lakshmanan, B., Sreekumar, C., John, L., Gomathinayagam, S., Mishra, A.K., Tewari, A.K. and Rao, J.R. (2007) Acridine Orange staining for quick detection of blood parasites. J. Vet. Parasitol.21: 85-86.

$* * * * * * * *$ 